\title{
Production of bioactive compounds by Streptomyces sp. and their antimicrobial potential against selected MDR uropathogens
}

\author{
Archana Singh* (D), Padma Singh \\ Kanya Gurukul Campus, Gurukul Kangri Deemed to be University, Haridwar, India.
}

\section{ARTICLE INFO \\ Article history: \\ Received on: May 08, 2021 \\ Accepted on: July 16, 2021 \\ Available online: November 10, 2021}

\section{Key words:}

Actinobacteria, uropathogens, multi-drug resistant, antibiotics, antimicrobial.

\begin{abstract}
Multi-drug resistance is increasing day by day and becoming a global health care issue. Hence, there is an urgent need to combat the multidrug resistance uropathogens, so the discovery of novel, efficient, and safe antibiotics from unexplored ecological niches is needed. Actinobacteria have great eminence of their potential for producing bioactive compounds. The aim of the present study is to explore some antimicrobial producing actinobacteria strains isolated from the soil. Our study was carried out with the goal of isolation and characterization of active strain of actinobacteria against uropathogens. Soil samples were collected from the Ganga riverbed, wheat and rice fields, Uttarakhand, India. Actinobacteria were isolated by serial dilution technique. A total of 19 actinobacteria were isolated and cross streaked against multidrug resistant uropathogens. Only seven strains of actinobacteria designed as ACG1, ACG4, ACG5, ACW9, ACW11, ACW14, and ACR17 showed good antimicrobial activity against Pseudomonas aeruginosa, Enterobacter sp., Bacillus subtilis, Staphylococcus aureus uropathogens. Among them, ACG1 showed a broad range of activity against all the tested uropathogens. Furthermore, the extracellular ethyl acetate extract of ACG1 showed maximum zone of inhibition against Enterobacter sp. $(23 \mathrm{~mm})$. ACG1 was identified based on morphological, cultural, physiological, and biochemical properties, as well as the $16 \mathrm{~S}$ ribosomal ribonucleic acid sequence, and was assigned the name S. atacamensis. It was deposited in GenBank under accession number (MW721229). Actinobacteria showed promising results so further studies are required to explore the potential as an antibiotic to cure life-threatening diseases like urinary tract infection.
\end{abstract}

\section{INTODUCTION}

Urinary tract infections (UTIs) are bacterial infections that can affect people of all age group and occur in the urinary tract. In our community, it's the most prevalent infection. Antibiotic resistance bacteria in UTIs are a serious issue and the most difficult challenge in public health care. Every year, millions of people worldwide are affected by UTI. Diabetic patients have a higher risk of developing UTI infection. Gram-negative bacteria play a vital role in UTI, and the most common causative agent is Escherichia coli (70\%-90\%) $[1,2]$. One of the major challenges in treating diseases such as malaria, tuberculosis, diarrhoeal disease, and UTI is the rapid development of drug resistance in pathogens [3,4]. Some novel approaches and provocations concerning drug-resistant pathogens have recently

\footnotetext{
*Corresponding Author

Archana Singh, Kanya Gurukul Campus, Gurukul Kangri Deemed to be University, Haridwar, India.E-mail: archanabeniwal026@gmail.com
}

been proposed, but more research is needed. There is an urgent medical need for new antimicrobial agents that are more essential than naturally occurring ones and have a novel mechanism of action. Soil is a highly used ecological niche in which the inhabitants produce secondary metabolites as well as biologically active natural products such as clinically essential antibiotics. Actinomycetes are a diverse group of filamentous prokaryotes which are usually Gram-positive Streptomyces has long been recognised as a rich source of useful secondary metabolites and continues to be a major source of novel bioactive molecules among actinomycetes [5-7]. The genus Streptomyces accounts for half of the total population of soil actinomycetes, and it produces $75 \%-80 \%$ of all antibiotics used commercially and medicinally [8]. Actinobacteria produce secondary metabolites such as peptide, alkaloids, sterols, fatty acids, terpenes, amino acid derivatives [9]. These secondary metabolites have previously been reported to have novel biological activities and the potential to be used in the development of antibiotics [10]. The number of multi-drug resistance pathogenic microbes has 
been increasing regularly and causing critical infections, but till now there are only limited therapeutic drugs that are applicable to combat these pathogens [11]. The loss of drug potency causes big problems, so there is a constant need for new, less toxic, more potent antibiotics to ensure that antibiotic-based treatments remain effective [12]. This study aims to identify novel antimicrobial representatives from Ganga River and agricultural farm soil against newly developed resistant microorganisms.

\section{MATERALS AND METHODS}

\subsection{Collection of Soil Samples and Isolation of Actinobacteria from Soil Samples}

Soil samples were collected from three different sites in Haridwar (Uttarakhand), the Ganga riverbed, wheat farms, and rice farms. The soil samples were collected from $15 \mathrm{~cm}$ depth using sterile poly beg and bring to the laboratory. These soil samples were air-dried for 3 days at $45^{\circ} \mathrm{C}$ crushed, and these soil samples were used for isolation. The serial dilution method and the spread plate technique were used to isolate actinobacteria [13]. In $9 \mathrm{ml}$ of sterile doubledistilled water, $1 \mathrm{~g}$ of soil was suspended. The dilutions are made up of $10^{-5}$. Aliquots $(0.1 \mathrm{ml})$ of $10^{-2}, 10^{-3}, 10^{-4}$ and $10^{-5}$ dilutions. These dilutions were spread on [starch casein Agar (SCA), glycerol yeast extract agar medium (GYEAM), Hi media] containing nalidixic acid $(100 \mathrm{mg} / 1)$ and fluconazole $(30 \mathrm{mg} / 1)$ and incubated at $24^{\circ} \mathrm{C}$ for 6-7 days $[14,15]$. Actinobacteria cultures were chosen and purified based on colony morphology. These were used for primary screening against uropathogens.

\subsection{Morphological, Physiological and Biochemical Observation}

A light microscope was used to examine the morphological and cultural characteristics of active isolates $[16,17]$. In different media, such as Mueller Hinton agar, morphological and cultural characters were observed. Actinobacteria (SCA), yeast peptone glucose agar, modified nutrient glucose agar medium. Actinobacteria isolates were differentiated by their colony characters, like size, shape, colour, consistency based on macroscopic observation $[18,19]$. Under the microscope, their mycelial structure was observed, and conidiospore and arthrosporic arrangements on the mycelia result of the isolates were compared with the actinobacteria morphology provided in Bergey's manual for the presumptive identification of isolates were recorded after incubation at $27^{\circ} \mathrm{C}$ for $7-14$ days [20], biochemical tests, and physiological tests were performed. $\mathrm{NaCl}$ resistance and temperature tolerance were also carried out as confirmatory tests [21].

\subsection{Isolation of Test Organisms}

Uropathogens were isolated from urine sample under the aseptic condition [22].

\subsubsection{Sample collection}

The samples were collected from BHEL hospital, Ranipur (Haridwar) patients of different age group, and the samples were fresh and midstream urine. Then, samples were packed in sterile bottles and transported to the laboratory for microbial analysis.

\subsubsection{Isolation of uropathogens}

The samples were shaken properly and made dilutions of urine samples. The uropathogens were isolated using the serial dilution method and the spread plate technique [13]. $9 \mathrm{ml}$ of sterile doubledistilled water was added to $1 \mathrm{ml}$ of fresh urine sample. The dilutions were then spread on medium. The freshly grown test bacteria were then isolated using a specific medium (Mac Conkey agar, Mannitol salt agar, Cetrimide agar) for 24 hours at $37^{\circ} \mathrm{C}$ [13].

\subsubsection{Phenotypic characterization of bacteria}

Isolated bacteria were identified by cultural characteristics such as abundance of growth, colour change in media, and morphological characteristics like form, size, margin, elevation studied on culture plate. Identified the isolates by Gram's staining, catalase, oxidase, nitrate reduction, IMVIC test, carbohydrate utilization, gelatine hydrolysis test, were performed for the confirmation of bacterial isolates according to the Bergey's manual [20].

\subsection{Antimicrobial Activity and Screening of Actinobacteria}

\subsubsection{Primary screening}

The antibiotic sensitivity of isolated actinobacteria was assayed by the cross-streak method [23]. First, the isolates inoculate as a single streak in the centre of the AIA medium plates and incubate at $28^{\circ} \mathrm{C}$ to $30^{\circ} \mathrm{C}$ for 7 days. After observing a good ribbon like growth of the actinobacteria at the centre of the plates, the test bacteria were streaked at right and left $90^{\circ}$ angle to the actinobacteria strain and incubated at $37^{\circ} \mathrm{C}$ for 24 hours. Based on the presence and absence of zone of inhibition, the antimicrobial compound producing actinobacteria were selected. The antimicrobial activity, which was indicated based on zone of inhibition. Further, the isolated producing zone of inhibition of $4 \mathrm{~mm}$ and above was only considered as antibiotic producers and selected for further study. The active isolate ACG1 filtrate was added with equal volume of three different solvents (methanol, chloroform, and ethyl acetate) and shaken for 1hour. The antimicrobial activity of extracted filtrate was tested against the selected uropathogens by agar well diffusion method [24].

\subsection{Medium Optimization}

The substrate mycelia of most active actinobacterial isolates were inoculated separately in different media for the production and put in an orbital shaker at $120 \mathrm{rpm}$ at $28^{\circ} \mathrm{C}$ for 8 days (GYEAM, SCA, AIA, ISP2). Following growth, the culture broth was centrifuged $(5,000 \mathrm{rpm})$ at $20^{\circ} \mathrm{C}$ for 20 minutes, and the supernatant was filtered using Whatman no 1 filter paper [25].

\subsection{Production and Extraction of Bioactive Compound}

For solvent extractions with ethyl acetate, the total culture filtrate of the most active strain ACG1 was used. The solvent and filtrate were shaken and mixed thoroughly at $1: 1(v / v)$ ratio. A separating funnel was used to collect the upper layer, and a 
rotatory evaporator was used to evaporate the solvent. Mycelia of active actinomycetes were soaked in methyl alcohol and kept in a shaker for the intracellular antibiotic compound, then crude extract was separated using a rotatory evaporator. Obtained residue was used to determine antimicrobial activity [26].

\subsection{Secondary Screening}

The disc diffusion method was used to test the antimicrobial activity of crude extract [27]. Mueller Hinton agar [Mueller Hinton Agar (MHA), HI media] plates were prepared for test pathogens. Then selected uropathogens were swabbed on the top of the solidified media. After that, $5 \mu \mathrm{g} /$ disc of crude extract was loaded by adding $10 \mu \mathrm{l}$ of prepared stock solution on a sterile filter paper disc (6 $\mathrm{mm}$ in diameter) and air dried. The disc was loaded with dimethyl sulfoxide as a negative control, while the positive control was levofloxacin $(5 \mu \mathrm{g} /$ disc $)$. The loaded discs were then placed on the medium's surface and allowed to diffuse for 30 minutes at room temperature. For 24 hours, the plates were incubated at $37^{\circ} \mathrm{C}$. After that, the zone of inhibition $(\mathrm{mm})$ was measured. The mean value of inhibition diameter (mean \pm standard error of the mean) was calculated from the triplicates assay [28].

\subsection{Genomic Studies of Potential Strain}

The selected actinobacteria strain was identified by $16 \mathrm{~S}$ ribosomal ribonucleic acid (rRNA) gene sequence was followed by Ref [29] from Biokart India Pvt Ltd Bangalore, Karnataka. Universal primers were used to amplify $16 \mathrm{~S}$ rRNA. Thirty-five cycles were performed with the actino specific forward primer (5'-GGATGAGCCCGCGGCCTA-3') and the actino specific reverse primer (5'-CGGTGTGTACAAGGCCCGG-3'). After ethidium bromide staining, polymerase chain reaction (PCR) amplification was detected using agarose gel electrophoresis. Then PCR product was sent to sequencing by automated sequence method. For sequencing, the same primers as previously reported were used. Further, National Center for Biotechnology information-basic local alignment search tool was also used to compare the sequence similarity of the actinobacteria strain. The $16 \mathrm{~S}$ rRNA a sequence of actinobacteria was deposited under GenBank. The original data set was re-sampled toll, 100 times using the phylogeny bootstrap program to obtain the confidence values for bootstrap analysis. The MEGA 4 software was used to create the phylogenetic tree using the bootstrapped data set. Using the neighbour joining method [30], the multiple distance matrixes were used to construct a phylogenetic tree.

\subsection{S rRNA Secondary Structure and Restriction Sites Analysis}

The NEB cutter online tool version 2.0 (nc2.neb.com/nebcutter2/) was used to find the restriction site [31], and the secondary structure of the $16 \mathrm{~S}$ recombinant deoxyribonucleic acid was predicted by Mfold software (http://unfold.rna.albany.edu/) to analyse the structural stability in terms of Gibb's free energy [32].

\section{RESULTS AND DISCUSSION}

In current study, 19 actinobacteria were isolated from soil samples from various locations. The distribution of actinobacteria varied with the texture and cultivation status of the soil, and the highest number was found in Ganga riverbed soil. The isolates were then purified by inoculating them into AIA medium. The pure strains were named as ACG1 and ACG2. GYEAM medium was used to keep these isolates alive and categorized according to their morphology that includes colony colour ranging from dark grey, light grey, dark brown, brown, whitish, and yellowish (Fig. 1) [16] and microscopic appearance of colonies after simple staining (Table 2) [17]. Test bacteria were isolated by using specific media like Mannitol salt agar was used for the identification of Staphylococcus sp. which ferments Mannitol, Cetrimide agar was used for the identification of Pseudomonas sp., MacConkey agar was used for the identification of lactose fermenting organism like Enterobacter family and Bacillus agar for the identification of Bacillus sp. [33]. By using these media, different organisms were identified tentatively based on colour change in media and colony morphology. We all know that UTIs are on the rise. Various antibiotics have been used, including cotrimoxazole, cephalosporins, and fluoroquinolones, but no one have been found to be superior. As a result, we must look for new antibiotics that are effective against resistant uropathogens. From three different soil samples, 19 different actinobacteria were isolated. Microbial pathogens were used to cross-streaked these strains. Four strains of uropathogens were chosen as test bacteria for the primary study. Primary screening showed that 17 colonies were able to produce antibiotics. Nineteen of the colonies ACG1, ACG4, ACG5,

Table 1: Morphological characterization was done by phenotypic visualization of colony on GYEA medium and colony margin and Gram reaction was depicted by light microscope.

\begin{tabular}{cllllll} 
Isolates & Aerial mycelium & $\begin{array}{l}\text { Substrate } \\
\text { mycelium }\end{array}$ & Soluble pigment & Colony Margin & $\begin{array}{c}\text { Growth } \\
\text { Gram } \\
\text { stain }\end{array}$ \\
ACG1 & Light grey & Dark grey & Dark green & Filamentous & ++ & + \\
ACG4 & White & Dark green & & Filamentous & + \\
ACG5 & Grey & Light yellow & & Filamentous & ++ \\
ACW9 & Creamy white & Brown & Yellow & Filamentous & ++ \\
ACW11 & Slimy yellow & Yellow & - & Filamentous & ++ \\
ACW14 & White grey & Yellow & - & Filamentous & ++ \\
ACR17 & Greyish & Brown & Brown & Filamentous & ++ \\
\hline
\end{tabular}

$(+++)=\operatorname{good}$ growth $(++)=$ moderate growth $(-)=$ no soluble; Gram stain $(+)=$ positive 


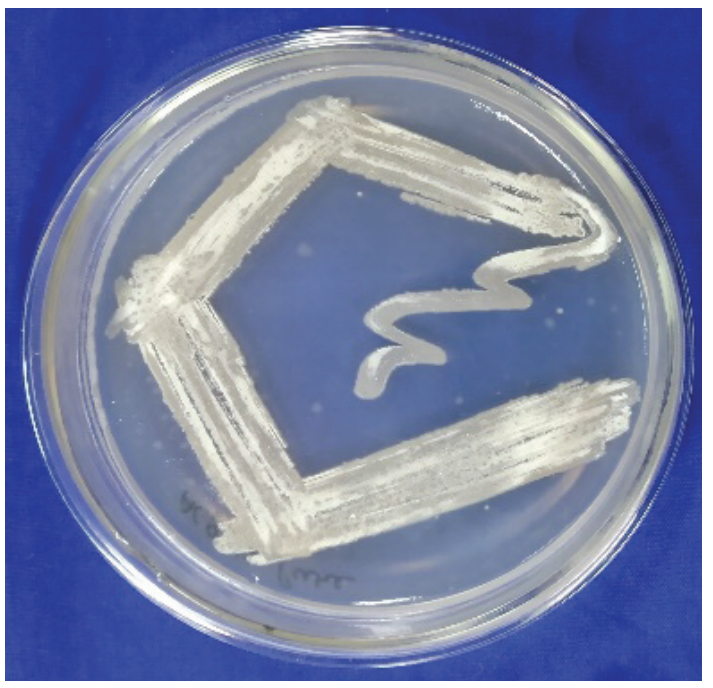

(a)

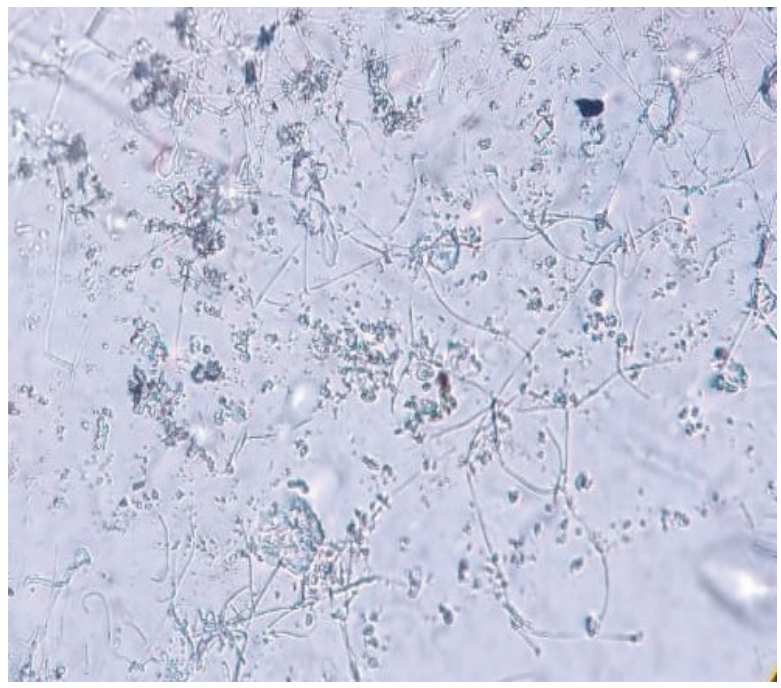

(b)

Figure 1: (a) Phenotypic characterization and (b) Microscopic view of S. atacamensis (ACG1).

Table 2: Biochemical characterization of Actinobacteria was done according to Bergy's mannual.

\begin{tabular}{|c|c|c|c|c|c|c|c|}
\hline Biochemical characterization & ACG1 & ACG4 & ACG5 & ACW9 & ACW11 & ACW14 & ACR17 \\
\hline Indole & - & - & - & - & - & - & - \\
\hline Methyl red & + & + & + & - & + & + & + \\
\hline $\mathrm{VP}$ & - & - & - & - & - & - & - \\
\hline Citrate utilization & + & + & + & - & + & + & + \\
\hline Nitrate Reduction & + & + & + & + & + & + & + \\
\hline Urease & - & - & - & - & - & - & - \\
\hline Catalase & + & + & + & + & + & + & + \\
\hline Oxidase & + & + & + & + & + & + & + \\
\hline Starch hydrolysis & + & + & + & + & + & + & + \\
\hline Gelatine Hydrolysis & + & + & + & + & + & + & + \\
\hline Lipid Hydrolysis & + & + & + & + & + & + & + \\
\hline Casein Hydrolysis & + & + & + & - & + & + & + \\
\hline
\end{tabular}

$(+)=$ positive $(-)=$ negative

Table 3: Biochemical characterization of test Uropathogens was done by according to Bergy's mannual.

\begin{tabular}{lcccc} 
Biochemical characterization & $\begin{array}{c}\text { Pseudomonas } \\
\text { aeruginosa } \\
(\mathbf{P 1})\end{array}$ & $\begin{array}{c}\text { Enterobacter tabaci } \\
(\mathbf{P 2})\end{array}$ & $\begin{array}{c}\text { Bacillus subtilis } \\
(\mathbf{P 5})\end{array}$ & $\begin{array}{c}\text { Staphylococcus aureus } \\
(\mathbf{P 6})\end{array}$ \\
$\begin{array}{l}\text { Starch hydrolysis } \\
\text { Fermentation }\end{array}$ & + & - & + & - \\
Lactose & - & - & - & - \\
Dextrose & - & - & $\mathrm{A}$ & $\mathrm{A}$ \\
Indole & $\mathrm{A}$ & - & - & $\mathrm{A}$ \\
MR reaction & - & + & - & - \\
VP reaction & - & + & + & + \\
Citrate & - & - & - & - \\
\hline
\end{tabular}


Singh and Singh: Production of bioactive compounds by Streptomyces sp. and their antimicrobial potential against selected MDR uropathogens 2021;9(06):71-79

Table 4: Primary screening was done by cross streak method and active isolates were calculated based on zone of inhibition between actinobacteria strain and test uropathogens.

\begin{tabular}{|c|c|c|c|c|}
\hline Isolates & $\begin{array}{c}\text { (P1) } \\
\text { Pseudomonas sp. } \\
\text { MEAN } \pm \mathrm{SE} \\
\mathrm{ZOI}(\mathrm{mm})\end{array}$ & $\begin{array}{c}(\mathrm{P} 2) \\
\text { Enterobacter sp. } \\
\mathrm{MEAN} \pm \mathrm{SE} \\
\mathrm{ZOI}(\mathrm{mm})\end{array}$ & $\begin{array}{c}\text { (P5) } \\
\text { Bacillus sp. } \\
\text { MEAN } \pm \text { SE } \\
\text { ZOI (mm) }\end{array}$ & $\begin{array}{c}\text { (P6) } \\
\text { Staphylococcus sp. } \\
\text { MEAN } \pm \text { SE } \\
\text { ZOI }(\mathbf{m m})\end{array}$ \\
\hline ACG 1 & $10.3 \pm 0.3$ & $11.3 \pm 0.6$ & $10.3 \pm 0.3$ & $11 \pm 0.5$ \\
\hline ACG 2 & $8.6 \pm 0.6$ & $10.3 \pm 0.3$ & $8.3 \pm 0.3$ & $11.3 \pm 0.6$ \\
\hline ACG 3 & - & - & - & - \\
\hline ACG 4 & $9.6 \pm 0.3$ & $9.3 \pm 0.3$ & $9.3 \pm 0.6$ & $7.3 \pm 0.3$ \\
\hline ACG 5 & $11 \pm 0.5$ & $8.6 \pm 0.6$ & $12.6 \pm 0.6$ & $1.6 \pm 0.3$ \\
\hline ACG 6 & - & - & - & - \\
\hline ACG 7 & $9.3 \pm 0.6$ & - & $9 \pm 0.5$ & - \\
\hline ACG 8 & - & - & - & - \\
\hline ACW 9 & $13.3 \pm 0.6$ & $11.6 \pm 0.3$ & $11.3 \pm 0.6$ & $9.6 \pm 0.6$ \\
\hline ACW 10 & - & - & - & - \\
\hline ACW 11 & $8.6 \pm 0.6$ & $9 \pm 0.5$ & $8.3 \pm 0.8$ & $12.6 \pm 0.6$ \\
\hline ACW 12 & $6.3 \pm 0.3$ & $9.3 \pm 0.6$ & $12.6 \pm 0.6$ & $9.3 \pm 0.6$ \\
\hline ACW 13 & - & - & - & - \\
\hline ACW 14 & $2 \pm 0.0$ & $9.6 \pm 0.3$ & $12.6 \pm 0.6$ & $11 \pm 0.6$ \\
\hline ACW 15 & - & - & - & - \\
\hline ACR 16 & $7.6 \pm 0.6$ & - & $7.3 \pm 0.3$ & - \\
\hline ACR 17 & $10.6 \pm 0.6$ & $10.3 \pm 0.3$ & $5.3 \pm 0.6$ & $9.3 \pm 0.3$ \\
\hline ACR 18 & - & - & - & - \\
\hline ACR 19 & $7.3 \pm 0.3$ & 8.6. \pm 0.6 & $6 \pm 0.0$ & \pm 0.6 \\
\hline
\end{tabular}

$(-)=$ no activity

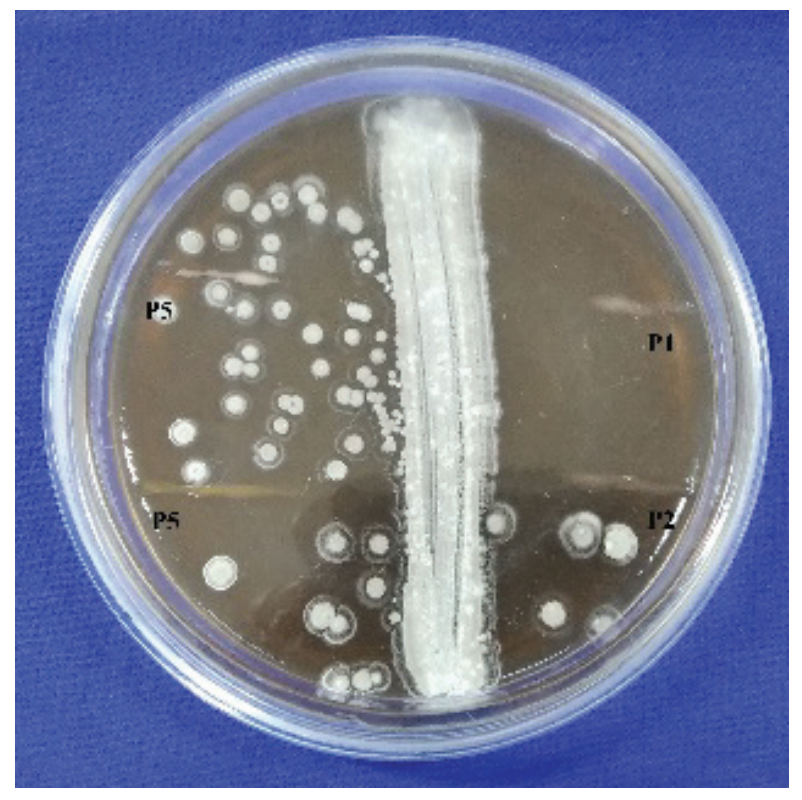

(a)

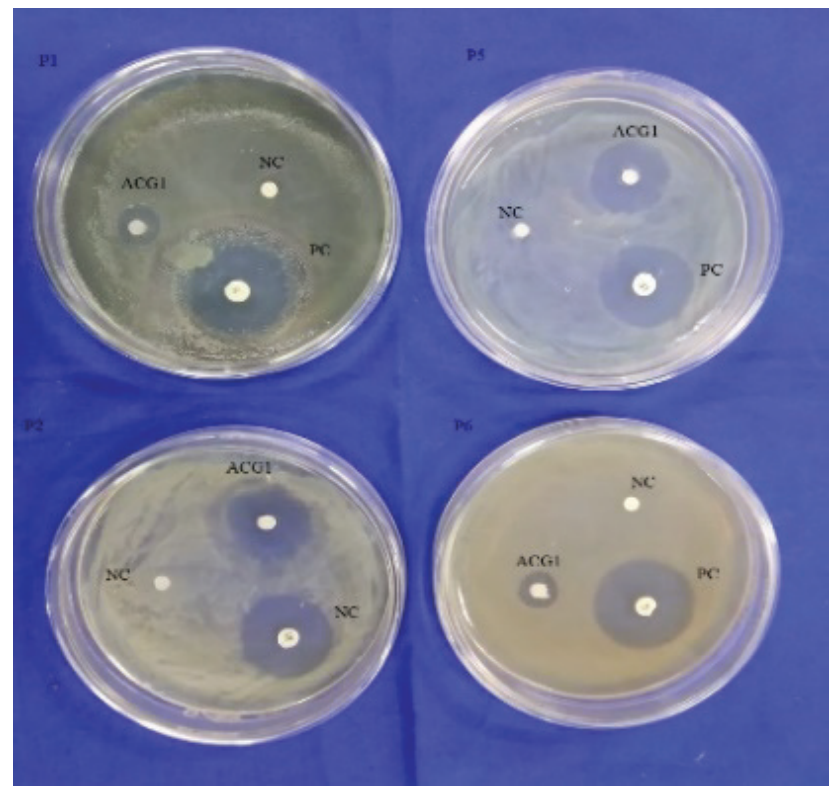

(b)

Figure 2: (a) Primary screening by cross streak method and (b) antimicrobial activity of ethyl acetate crude extract of S. atacamencis (ACG1) by disc diffusion method against selected uropathogens (P1) Pseudomonas aeruginosa, (P2) Enterobacter tabaci (P5) Bacillus subtilis, (P6) Staphylococcus aureus. 


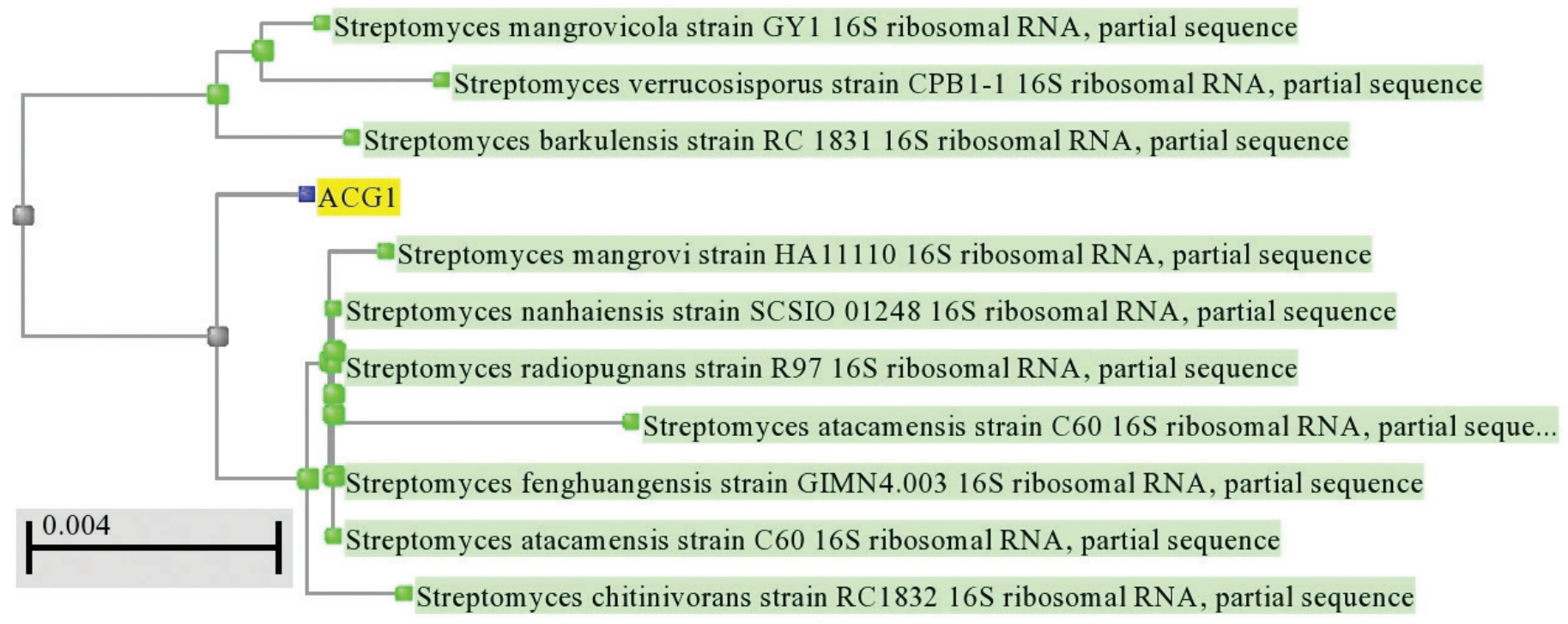

Figure 3: Phylogenetic tree indicating the taxonomic position of S. atacamensis (ACG1).

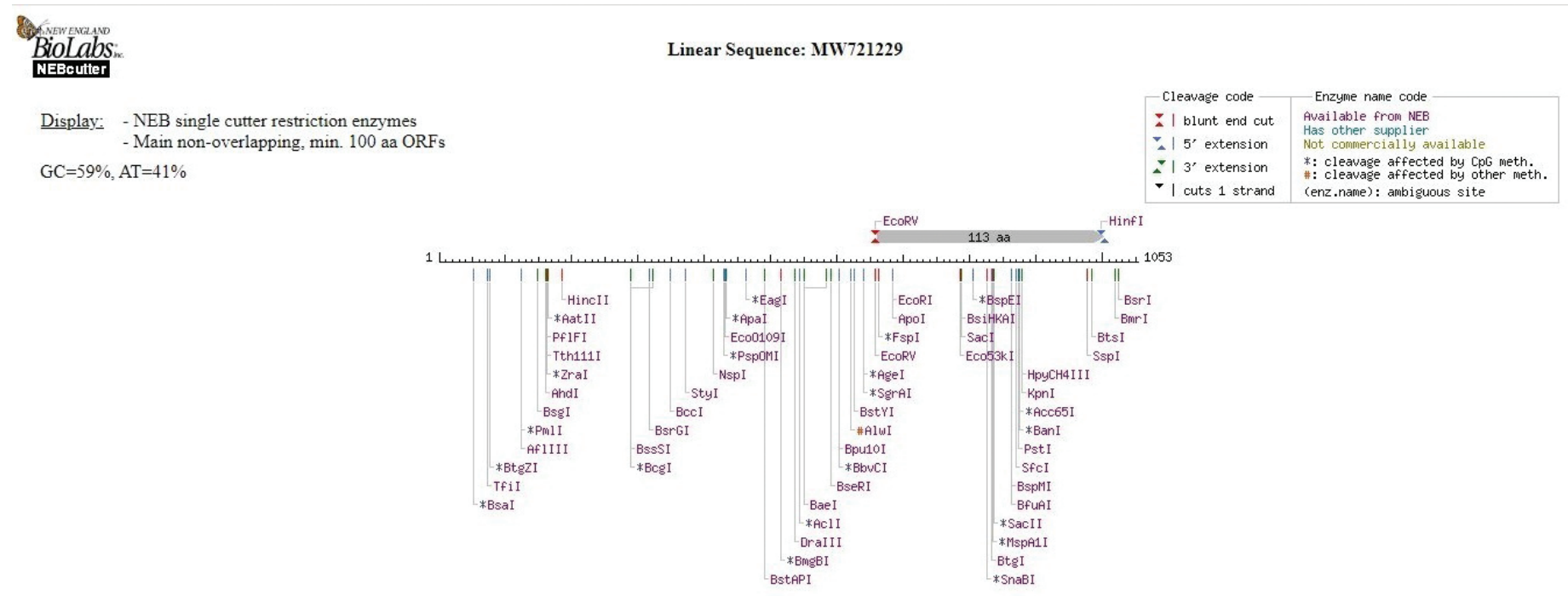

Figure 4: Restriction sites on the 16S rRNA sequence of $S$. atacamensis (ACG1).

ACW9, ACW11, ACW14, and ACR17 showed great promise for antibiotic production with a large zone of inhibition against UTI pathogens (Table. 4). The primary screening clearly shows that ACG1, ACG4, ACG5, ACW9, ACW11, ACR14, and ACR17 possessed very high antimicrobial potential against uropathogens. The results of the present study are comparable with previous study [21]. Streptomyces is responsible for approximately $80 \%$ of total antibiotic production [26]. Furthermore, about 10-20 compounds are used in agriculture, primarily as pesticides, herbicides, plant protectants, and food additives. Understanding the existence of microbial species in natural ecosystems depends on their isolation and characterization. The isolation of a wide range of novel and diverse actinobacteria provides a theoretical framework for exploiting and utilising actinobacterial resources [34]. As shown in Table 4, among the seven strains, ACG1 gives broad spectrum activity, so this strain was used for optimization. Which inhibited all human pathogens when grown on International Streptomyces Project-2 (ISP-2) media. Among three solvents (methanol, chloroform, and ethyl acetate), only ethyl acetate extract showed better inhibition in comparison to chloroform and methanol extract. The active strain ACG1's extracellular ethyl acetate crude extract had good activity against all selected uropathogens. (Fig. 2) [35]. The results clearly demonstrate difference between the activity of crude extracts and pure antibacterial drug (levofloxacin) showing higher, equivalent, or lesser zone of inhibition. The isolated active strain ACG1 was found to have $99.72 \%$ homology to the $S$. atacamensis strain C60 16S rRNA Sequence ID: NR 108859.1 and was submitted to GenBank (MW721229). The DNA sequence was 


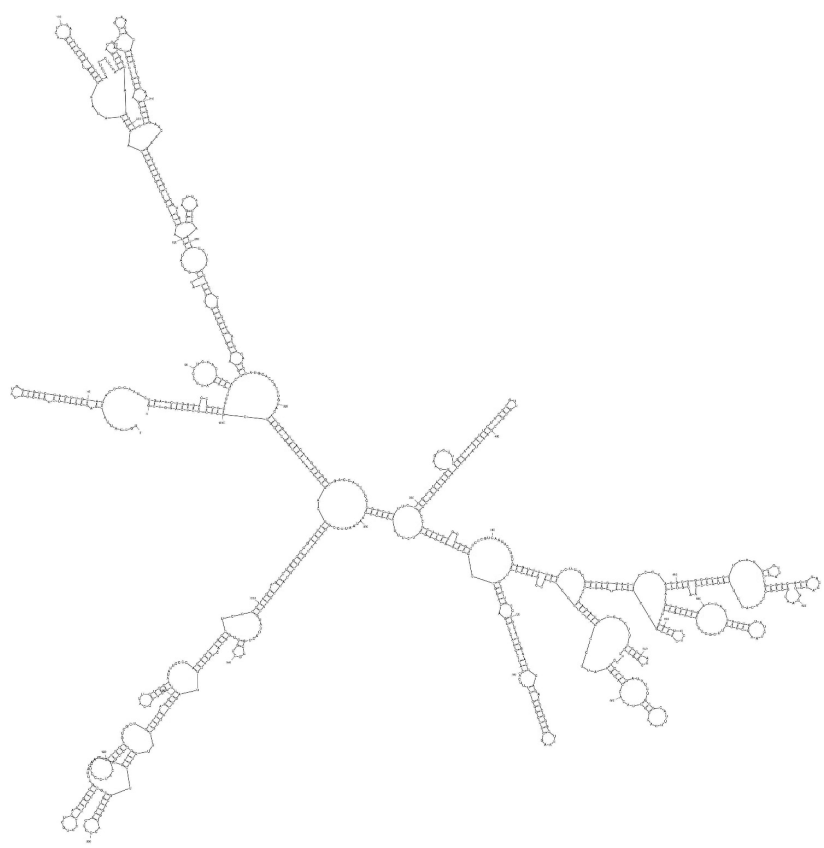

$d G=-332.46[$ [Iitially -371.20$]$ MW721229

Figure 5: Secondary structure of $16 \mathrm{~S}$ rRNA sequence of $S$. atacamensis (ACG1) aligned, and a phylogenetic tree was constructed by using aligner software and the result revealed that ACG1 indicated similarly to (Fig. 3). The guanine cytosine adenine thymine content was found to be present in $59 \%$ and $41 \%$ of the $16 \mathrm{~S}$ rRNA sequence of ACG1 (Fig. 4). The predicted structure's energy was $332.46 \mathrm{kcal} /$ mol (Fig. 5). It was discovered that about half of all actinobacteria strains produced antibiotics as a result of this research. The most effective against uropathogens is an isolated strain from the Ganga riverbed. The actinobacterial community of the samples was investigated by primary culturing on MHA and starch casein agar media by serial dilution method. After 20 days of incubation, no other bacterial colony appears when actinobacteria are grown on

Table 6: Secondary screening of active isolate (ACG1) was done by disc diffusion method. The active isolates was calculated based on zone of inhibiton.

\begin{tabular}{lccc} 
Test Bacteria & \multicolumn{3}{c}{$\begin{array}{c}\text { Zone of Inhibition (mm) } \\
\text { MEAN } \pm \text { SE }\end{array}$} \\
& $\begin{array}{c}\text { Crude Extract } \\
\text { of Streptomyces } \\
\text { atacamencis } \\
\text { (ACG1) }\end{array}$ & $\begin{array}{c}\text { Positive Control } \\
\text { Levofloxacin } \\
(5 \mathrm{ug} / \text { disc })\end{array}$ & $\begin{array}{c}\text { Negative } \\
\text { Control } \\
\text { DMSO }\end{array}$ \\
$\begin{array}{l}\text { Pseudomonas } \\
\text { aeruginosa } \text { P1 }\end{array}$ & $7.3 \pm 0.33$ & $6.3 \pm 0.33$ & - \\
$\begin{array}{l}\text { Enterobacter } \\
\text { tabaci } \text { P2 } \\
\text { Bacillus } \\
\text { subtilis } \text { P5 }\end{array}$ & $22.3 \pm 0.33$ & $19.3 \pm 0.33$ & - \\
$\begin{array}{l}\text { Staphylococcus } \\
\text { aureus } \text { P6 }\end{array}$ & $16.3 \pm 0.88$ & $13.3 \pm 0.66$ & - \\
\hline
\end{tabular}

\pm (Stander error)

Table 5: Morphological feature of Streptomyces atacamencis (ACG1) on different culture media (AIA, GYEA, SCA ISP-2) was done by phenotypic visualization.

\begin{tabular}{|c|c|c|c|}
\hline S.NO & Media & Morphological characteristics & ACG 1 \\
\hline \multirow[t]{4}{*}{1} & \multirow{4}{*}{ Actinomycete Isolation Agar (AIA) } & Aerial Mycelium & Light Grey \\
\hline & & Substrate Mycelium & Dark Grey \\
\hline & & Diffusible Pigment & - \\
\hline & & Growth & + \\
\hline \multirow[t]{4}{*}{2} & \multirow[t]{4}{*}{ Glycerol Yeast Extract Agar (GYEA) } & Aerial Mycelium & Grey \\
\hline & & Substrate Mycelium & Dark Grey \\
\hline & & Diffusible Pigment & Brown \\
\hline & & Growth & +++ \\
\hline \multirow[t]{4}{*}{3} & \multirow[t]{4}{*}{ Starch Casein Agar (SCA) } & Aerial Mycelium & White \\
\hline & & Substrate Mycelium & Dull White \\
\hline & & Diffusible Pigment & - \\
\hline & & Growth & ++ \\
\hline \multirow[t]{4}{*}{4} & \multirow[t]{4}{*}{ Yeast and Malt extract medium (ISP-2) } & Aerial Mycelium & Grey \\
\hline & & Substrate Mycelium & Brown \\
\hline & & Diffusible Pigment & - \\
\hline & & Growth & +++ \\
\hline
\end{tabular}

$(-)=$ no pigment, $(+++)=$ Good growth,$(++)=$ Moderate growth, $(+)=$ Weak growth 
MHA medium. The best inhibition of the strains was determined on the 3rd day of incubation. ACG1 showed the best antimicrobial activity against uropathogens. The growth increased on the 7 th day of incubation, and the activity against uropathogens was found to be excellent. According to our findings, the bacterial community of the Ganga riverbed soil is a rich source of best actinobacteria.

\section{CONCLUSION}

Our study suggests that Ganga riverbed soil is considered as a good source of a wide variety of interesting actinomycetes species. We know that actinomycetes have antibacterial properties and they could be used as potent drug candidates in pharmaceutical preparations. The soil microflora is the great source of novel actinomycetes, so we need to further explore the study of actinomycetes species, which has the ability to synthesis a wide range of bioactive compounds that could be used safely for human therapeutics as well as a variety of industrial applications would be extremely beneficial. The biocompatible compound extracted from this potent streptomyces sp. will aid in the development of antibiotics to combat drug-resistant uropathogens. That's why further research is in progress to produce bioactive compounds on a large scale.

\section{ACKNOWLEDGEMENT}

The authors are thankful to the Department of Microbiology, Girls campus, Gurukul Kangri Vishwavidhyalaya, Haridwar providing all the necessary facilities required to carry out the research work. The authors are also thankful to Biokart India Pvt Ltd, Bangalore providing molecular facilities.

\section{REFERENCES}

1. Karlowsky JA, Kelly LJ, Thornsberry C, Jones ME, Sahm DF. Trends in antimicrobial resistance among urinary tract infection isolates of Escherichia coli from female outpatients in the United States. Antimicrob Agents Chemother 2002;46:2540-5.

2. Nakhjavani FA, Mirsalehian A, Hamidian M, Kazemi B, Mirafshar M, Jabalameli F. Antimicrobial susceptibility testing for Escherichia coli strains to fluoroquinolones, in urinary tract infections. Iran J Public Health 2007:89-92.

3. Subramanian M, Ganesapandian S, Singh M, Kumaraguru A. Antimicrobial susceptibility pattern of urinary tract infection causing human pathogenic bacteria. Asian J Med Sci 2011;3:56-60.

4. Kerr JR. Antibiotic treatment and susceptibility testing. Antibiotic treatment and susceptibility testing. J Clin Pathol 2005;58:786-7.

5. Li B, Jiang B, Boyce BM, Lindsey BA. Multilayer polypeptide nanoscale coatings incorporating IL-12 for the prevention of biomedical device-associated infections. Biomaterials 2009;30:25528.

6. Boyce BM, Lindsey BA, Clovis NB, Smith ES, Hobbs GR, Hubbard DF, et al. Additive effects of exogenous IL-12 supplementation and antibiotic treatment in infection prophylaxis. J Orthop Res 2012;30:196-202.

7. Armstead AL, Li B. Nanomedicine as an emerging approach against intracellular pathogens. Int J Nanomed 2011;6:3281.

8. Mellouli L, Ameur-Mehdi RB, Sioud S, Salem M, Bejar S. Isolation, purification and partial characterization of antibacterial activities produced by a newly isolated Streptomyces sp. US24 strain. Res Microbiol 2003;154:345-52.

9. Jimenez JT, Sturdíkova M, Sturdík E. Natural products of marine origin and their perspectives in the discovery of new anticancer drugs. Acta Chim Slov 2009;2:63-74.
10. Kumari N, Mithal R, Menghani E. Actinomycetes as antimicrobial agents: an overview. J Agroecol Nat Resour Manage 2015;2:248-50.

11. Demain AL, Sanchez S. Microbial drug discovery: 80 years of progress. J Antibiot 2009;62:5-16.

12. Vander Waaij D, Nord CE. Development and persistence of multiresistance to antibiotics in bacteria; an analysis and a new approach to this urgent problem. Int J Antimicrob Agents 2000;1:191-7.

13. Waksman SA. The Actinomycetes. Vol. II. Classification, identification and descriptions of genera and species. Tindall \& Cox Ltd, Baillière, London, p 2, 1961.

14. Thawai C, Tanasupawat S, Itoh $\mathrm{T}$, Suwanborirux $\mathrm{K}$, Kudo $\mathrm{T}$. Micromonospora aurantionigra sp. nov., isolated from a peat swamp forest in Thailand. Actinomycetologica 2004;18:8-14.

15. Arifuzzaman $M$, Khatun MR, Rahman $H$. Isolation and screening of actinomycetes from Sundarbans soil for antibacterial activity. Afr J Biotechnol 2010;9:4615-9.

16. Goodfellow M, Haynes JA. Actinomycetes in marine sediments, In:Oritz L, Bojali CF, Yakoleff V, (eds.). Biological, biochemical and biomedical aspects of actinomycetes. Academic Press, New York, London, vol. 21:453-63, 1984.

17. Shirling EB, Gottlieb D. Methods for characterization of Streptomyces species. Int J Syst Bacteriol 1966;16:313-40.

18. Kumar PS, Raj JP, Duraipandiyan V, Ignacimuthu S. Antibacterial activity of some actinomycetes from Tamil Nadu, India. Asian Pac J Trop Biomed 2012;2:936-43.

19. Lakshmipathy DT, Kannabiran K. A morphological, biochemical and biological studies of halophilic Streptomyces sp. isolated from saltpan environment. Am J Infect Dis 2009;5:200-6.

20. Holt JG, Krieg NR, Sneath PH, Staley JT, Williams ST. Bergey's manual of determinative bacteriology, actinomycetales. 9th ed. Williams \&Wilkins, Baltimore, MD, 605-9, 2000.

21. ShaikM,SankarGG, IswaryaM, RajithaP. Isolationand characterization of bioactive metabolites producing marine Streptomyces parvulus strain sankarensis-A10. J Genet Eng Biotechnol 2017;15:87-94.

22. Kadhum SJ, Muhaiesen SH. Isolation of uropathogens from pediatric associated UTI, with special focus on the detection of proteus vulgaris. Iraqi J Biotechnol 2015;14:77-84.

23. Oskay M. Antifungal and antibacterial compounds from Streptomyces strains. Afr J Biotechnol 2009;8:3007-17.

24. Rajivgandhi G, Vijayan R, Kannan M, Santhanakrishnan M, Manoharan N. Molecular characterization, and antibacterial effect of endophytic actinomycetes Nocrdiopsis sp. GRG1(KT235640) from brown algae against MDR strains of uropathogens. Bioact Mater 2016;1:140-50.

25. Kumar PS, Duraipandiyan V, Ignacimuthu S. Isolation, screening and partial purification of antimicrobial antibiotics from soil Streptomyces sp. SCA 7. Kaohsiung J Med Sci 2014;30:435-46.

26. Liu CM, Westly JW, Herman TE, Prasser BLT, Palleroni N, Evans $\mathrm{RH}$, et al. Novel polyether antibiotics. X-14873 A, G and H produced by streptomyces. Taxonomy of the producing culture, fermentation, biological and ionospheres properties of antibiotics. J Antibiot 1986;39:1712-18.

27. Thekkangil A, Suchithra TV. Antidermatophytic lead compounds from Streptomycetes albidoflavus STV1572a against Tinea infections by Tricophyton mentagrophytes. Microb Pathog 2020;142:104-37.

28. Sharma D, Kaur T, Chadha BS, Manhas RK. Antimicrobial activity of actinomycetes against multidrug resistant Staphylococcus aureus, E. coli and various other pathogens. Trop J Pharm Res 2011;10:801-8.

29. Tamura K, Dudley J, Nei M, Kumar S. MEGA4: molecular evolutionary genetics analysis (MEGA) software version 4.0. Mol Biol Evol 2007;28:1596-9.

30. Das R, Romi W, Das R, Sharma HK, Thakur D. Antimicrobial potentiality of actinobacteria isolated from two microbiologically unexplored forest ecosystems of Northeast India. BMC Microbiol 2018;18:1-6.

31. Ganesan P, Reegan AD, David RHA, Gandhi MR, Paulraj MG, AlDhabi NA, et al. Antimicrobial activity of some actinomycetes from 

selected MDR uropathogens 2021;9(06):71-79

western ghats of Tamil Nadu, India. Alexandria J. Med 2017;2: 101-10.

32. Zuker M. Mfold web server for nucleic acid folding and hybridization prediction. Nucleic Acids Res 2003;13:3406-15.

33. Pallavi, Singh P. Antimicrobial potential of Actinobacteria against food borne microorganisms. Pharm Innovation 2019;8:95-9.

34. Moncheva P, Tishkov S, Dimitrova N, Chipeva V, Antonova-Nikolova $\mathrm{S}$, Bogatzevska N. Characteristics of soil actinomycetes from Antarctica. J Cul Coll 2002;35:58-67.

35. Balachandar R, Karmegam N, Saravanan M, Subbaiya R, Gurumoorthy P. Synthesis of bioactive compounds from vermicast isolated actinomycetes species and its antimicrobial activity against human pathogenic bacteria. Microb. Pathog 2018;121:155-65.

How to cite this article:

Singh A, Singh P. Production of bioactive compounds by Streptomyces sp. and their antimicrobial potential against selected MDR uropathogens. J Appl Biol Biotech 2021;

9(06):71-79. 